\title{
HEART RATE RECOVERY IN PATIENTS WITH ISCHEMIC HEART DISEASE - RISK FACTORS
}

\author{
COSMIN GRAD ${ }^{1}$, DUMITRU ZDRENGHEA ${ }^{2}$
}

\author{
${ }^{1}$ Second Medical Department, Iuliu Hatieganu University of Medicine and \\ Pharmacy, Cluj Napoca, Romania \\ ${ }^{2}$ Department of Cardiology-Rehabilitation Hospital, Iuliu Hatieganu University \\ of Medicine and Pharmacy, Cluj-Napoca, Romania
}

\begin{abstract}
Background and aim. Central nervous system dysfunction is associated with mortality and morbidity in patients with cardiovascular disease, post-workout recovery and faster heart rate being mediated by the dynamic interaction between the sympathetic nervous system (SNS) and the parasympathetic nervous system (PNS), as components of the autonomic nervous system. Heart rate recovery is the decline in heart rate after exercise. The aim of the study was to determine the influence of certain clinical and paraclinical parameters on heart rate recovery after exercise in patients with ischemic heart disease.

Methods. The study included 260 patients who were subjected to cardiovascular stress test.

The following parameters were measured in each patient: blood pressure and pulse rate prior to exercise, during exercise and at protocol-established time intervals, as well as 1 and 3 minutes after the end of the stress test. Statistical analysis was performed usingMedCalc software version 14.8.1

Results. Elderly patients had slower heart rate recovery at 1 minute after effort. Female patients have recovered significantly better the heart rate, at 1 minute and 3 minutes after effort compared to the males. This difference was maintained in multivariate analysis, independent of age or comorbidities of patients. The presence of ischemic heart disease was the most important factor independently associated with HRR1.Triglyceride values were negatively correlated with both HRR 3 and HRR1 and independent of other factors present in the multivariate analysis.

Conclusions. Autonomic dysfunction is involved in the development of cardiovascular risk factors like hypertension, diabetes, dyslipidemia and was directly correlated with morbidity and mortality caused by coronary heart disease.
\end{abstract}

Keywords: heart rate recovery, ischemic heart disease, stress test, risk factors

\section{Introduction}

Central nervous system dysfunction is associated with mortality and morbidity in patients with cardiovascular disease, post-workout recovery and faster heart rate being mediated by the dynamic interaction between the sympathetic nervous system (SNS) and the parasympathetic

Manuscript received: 02.12.2014

Accepted: 16.12.2014

Address for correspondence: grdcos@yahoo.com nervous system (PNS), as components of the autonomic nervous system $[1,2]$. Sympathetic tone prevails during workout determining the increase in heart rate, whereas cardiac vagal tone mediates heart rate recovery attaining rest values.

High resting heart rate (HR), low resting heart rate variability, failure to achieve the target HR during workout (chronotropic incompetence) and slow heart rate recovery (HRR) are markers of cardiovascular autonomic dysfunction. 
Heart rate recovery is the decline in heart rate after exercise [3]. Heart rate decrease after exercise follows a pattern of exponential decline. Heart rate is the slowest at the beginning of the recovery period and then, frequency recovery rate gradually decreases until resting heart rate values are achieved $[4,5,6]$. The main factor governing the recovery rate is the autonomic nervous system (ANS), specifically the relationship between the sympathetic and parasympathetic nervous system components. Cardiac arrhythmia and sudden cardiac death are more common in those with increased sympathetic activity and decreased parasympathetic activity (autonomic dysfunction).

Immediately after exercise, PNS increases its influence on the heart and SNS withdraws the influence in order to reduce HR [7-11]. HRR was examined throughout shorter periods of time, the first 30 and 120 seconds of recovery, using PNS and SNS blockade. The conclusion was that the first 30 seconds of HRR are not affected by sympathetic blockade and exercise intensity. Therefore, it seems that PNS reactivation is the primary regulator of HRR in the first 30 seconds of recovery [12].

A growing number of studies show that the rate of the decline in heart rate (heart rate recovery) is associated with cardiovascular mortality from all causes. Better survival rates are associated with faster heart rate recovery being considered to reflect an increase in vagal tone associated with improved fitness and better cardiovascular health. In recent years, heart rate recovery has been recognized as a powerful prognostic marker in patients with cardiovascular disease, probably because it reflects cardiac vagal modulation (dysfunction).

The autonomic nervous system is difficult to investigate because there is a fine control of the cardiovascular system, from the arterial and venous constriction to the heart rate. In normal individuals, dual innervation (from both sympathetic and parasympathetic neurons) allows simultaneous antagonistic actions. The sympathetic nervous system increases stroke volume, heart rate, arterial and venous constriction, and increases cardiac contractility, while the parasympathetic nervous system inhibits these functions. Autonomic dysfunction is involved in the development of cardiovascular risk factors such as hypertension, diabetes mellitus, being directly related to morbidity and mortality caused by coronary heart disease (including sudden cardiac death) and total mortality.

Slow heart rate recovery after effort and metabolic syndrome are predictors of cardiovascular morbidity and mortality. Metabolic syndrome is a risk factor for cardiovascular disease and diabetes mellitus and it is defined by threshold values for main components: waist circumference, HDL cholesterol, triglycerides, blood pressure, blood sugar levels. The pathogenesis of the metabolic syndrome also includes insulin resistance [13]. Delayed heart rate recovery is a risk factor for cardiovascular mortality and mortality from all causes in healthy individuals [14-17], in those with cardiovascular disease $[18,19]$ and in men with diabetes mellitus. Associations have been found between heart rate recovery, metabolic syndrome and its components.

Atherosclerotic vascular disease is common in the general population and affects most adults over the age of 60 years. The presence of atherosclerotic disease in any vascular territory is now recognized to significantly increase the risk of CVD in other vascular territories. Many of the key risk factors for cardiovascular disease are modifiable through specific preventive measures.

These included smoking, dyslipidemia, hypertension, diabetes mellitus, abdominal obesity, psychosocial factors (such as depression, perceived stress, life events), daily consumption of fruits and vegetables, regular alcohol consumption and regular physical activity.

\section{Objectives}

The aim of the study was to determine the influence of certain clinical and paraclinical parameters on heart rate recovery after exercise in patients with ischemic heart disease.

\section{Material and method}

The study was conducted at the Rehabilitation Clinical Hospital between 2011-2013.

It was an observational, analytical, prospective cohort study. Data collection was done according to the exposed - non-exposed type.

Subjects were included in the study after meeting the inclusion criteria and after signing a consent form for enrolment. The study protocol was approved by the Ethics Committee of "Iuliu Hatieganu" University of Medicine and Pharmacy Cluj-Napoca.

The study included 260 patients who were subjected to cardiovascular stress test. Subjects had a mean age of $56.2 \pm 10.4$ years, with a minimum of 18 and a maximum of 79 years. The study included 135 (51.9\%) men and 125 (48.1\%) women.

The indications for the stress test included: diagnosis and risk stratification of patients with suspected ischemic heart disease, determining disease severity in patients with clear diagnosis of ischemic cardiomyopathy, monitoring patients throughout medical treatment or intervention.

Before the stress test, patients had undergone echocardiography using a Esaote MyLab X-View 50 ultrasound machine, manufactured in 2008, with a linear variable 7.5-10 MHz frequency probe, Doppler color.

No effort test was conducted in patients who had indications of one of the following diagnoses: heart attack (within the past 2 days), unstable angina not stabilized by medical therapy, symptomatic uncontrolled arrhythmia, decompensated heart failure, pulmonary thromboembolism, acute pericarditis or myocarditis, aortic dissection, severe symptomatic aortic valve stenosis, uncontrolled BP 
(200/100 mm Hg), hypertrophic cardiomyopathy, highgrade atrio-ventricular block.

The stress test was performed by a specialist cardiologist with experience in this department. The test was performed using a cycloergometer.

The following parameters were measured in each patient: blood pressure and pulse rate prior to exercise, during exercise and at protocol-established time intervals, as well as 1 and 3 minutes after the end of the stress test. The following were reasons for stopping the stress test: chest pain, fatigue, dyspnea, pressor response.

A series of clinical and laboratory data were assessed in patients included in the study. Patient history helped identify the presence of diabetes mellitus, essential hypertension, ischemic heart disease.

The diagnosis of ischemic heart disease was determined by medical history, electrocardiogram (ECG), echocardiography or coronarography results. The following were clinical features: constrictive discomfort, pressure or burning, location in the chest, jaw, shoulder, back, arms, occurring during physical effort, emotional stress, or at rest. The pain may be of variable duration and it can disappear following cessation of effort or following sublingual nitroglycerin administration. The ECG monitored the presence of the following elements: changes in the STsegment (significant elevation or depression), pathological Q wave, negative or flat $\mathrm{T}$ wave, bundle branch block, ventricular hypertrophy. Echocardiography determined the presence of kinetic changes in the ventricles (hypokinesia, akinesia, dyskinesia).

The lipid profile was determined for each patient: total cholesterol (normal value between 140-200 mg/dl), HDL cholesterol (normal value greater than $40 \mathrm{mg} / \mathrm{dl}$ in men and greater than $50 \mathrm{mg} / \mathrm{dl}$ in women), LDL cholesterol (normal value lower than $100 \mathrm{mg} / \mathrm{dl}$ ), triglycerides (normal value between $50-150 \mathrm{mg} / \mathrm{dl}$ ).

Statistical analysis was performed using MedCalc software version 14.8.1. Data were considered as nominal or quantitative. The normal distribution of continuous variables was examined using the Kolmogorov-Smirnov test. The frequency and percentage were reported for nominal data, and the mean and standard deviation were reported for continuous data.

The comparison between two groups of a continuous variable was performed using the independent samples t-test. The correlation between two variables was tested using Pearson's correlation. Percentage differences between two groups of nominal variables were assessed using the chi-square test.

Multivariate analysis consisted of the construction of several multiple linear regression models.

A $p$ value of 0.05 was considered statistically significant.

\section{Results}

Patients included in the study had a mean age of $56.2 \pm 10.4$ years, with a minimum of 18 years and a maximum of 79 years. The study included 135 (51.9\%) men and 125 (48.1\%) women.

Resting heart rate (before exercise) (HRrest) was $78.3 \pm 14.1$ beats per minute (bpm). Maximum heart rate (HRmax) recorded during the stress test was $114.8 \pm 20.4$ bpm. Pulse rate measured 1 minute after the stress test(HR1) was $96.4 \pm 18.8 \mathrm{bpm}$. Pulse rate measured 3 minutes after the stress test(HR3) was $81.7 \pm 15.5 \mathrm{bpm}$. Heart rate recovery at 1 minute (HRR1) was $18.4 \pm 10.3 \mathrm{bpm}$ and heart rate recovery at 3 minutes (HRR3) was $33.1 \pm 15.8 \mathrm{bpm}$.

The study included $162(63.2 \%)$ patients with ischemic cardiomyopathy (IC). Differences related to age, gender and stress test parameters can be seen in (Tab. 1)

Table 1. Heart rates in patients with and without ischemic cardiomyopathy (IC).

\begin{tabular}{lcccc}
\hline Variable & $\begin{array}{c}\text { Patients } \\
\text { with IC }\end{array}$ & $\begin{array}{c}\text { Patients } \\
\text { without IC }\end{array}$ & $\mathrm{p}$ \\
\hline Age (years) & $58.4 \pm 8$ & $52.6 \pm 12.9$ & $<0.001$ \\
\hline \multirow{2}{*}{ Gender } & Women & $81(64.8 \%)$ & $44(35.2 \%)$ & \multirow{2}{*}{0.4} \\
\cline { 2 - 4 } & Men & $81(60 \%)$ & $54(40 \%)$ & \\
\hline HRrest (bpm) & $76.3 \pm 13.2$ & $81.6 \pm 15$ & 0.004 \\
\hline HRmax (bpm) & $111.3 \pm 19.4$ & $120.9 \pm 20.7$ & $<0.001$ \\
\hline HR1 (bpm) & $95.4 \pm 18.4$ & $98 \pm 19.4$ & 0.2 \\
\hline HRR1 (bpm) & $15.8 \pm 10$ & $22.8 \pm 9.4$ & $<0.001$ \\
\hline HR3 (bpm) & $78.7 \pm 12.9$ & $86.8 \pm 18$ & $<0.001$ \\
\hline HRR3 (bpm) & $32.5 \pm 15.9$ & $34 \pm 15.5$ & 0.4 \\
\hline
\end{tabular}

There was a low statistically significant negative correlation between patient age values and HRR1 values $(r=-0.176 ; p=0.004)$. There was no statistically significant correlation between patient age and HRR3 values $(\mathrm{r}=-$ $0.104 ; \mathrm{p}=0.09)$. HRR1 values were statistically significantly higher in women $(20 \pm 10 \mathrm{bpm})$ than in men $(16.8 \pm 9.9 \mathrm{bpm})$ $(\mathrm{p}=0.01)$. HRR3 values were statistically significantly higher in women $(37.4 \pm 15.8 \mathrm{bpm})$ than in men $(29 \pm 14.6$ bpm) $(\mathrm{p}<0.001)$.

There were 14 (5.4\%) smokers in the study. HRR1 values were not statistically significantly higher in smokers $(19.2 \pm 6.9 \mathrm{bpm})$ than in non-smokers $(18.3 \pm 10.5 \mathrm{bpm})$ $(\mathrm{p}=0.7)$. HRR 3 values were not statistically significantly higher in non-smokers $(33.2 \pm 16 \mathrm{bpm})$ than in smokers $(30.7 \pm 10 \mathrm{bpm})(\mathrm{p}=0.5)$.

Hypertension was present in $214(82.3 \%)$ patients. HRR1 values were statistically significantly higher in patients without hypertension $(24 \pm 10.9 \mathrm{bpm})$ than in those with hypertension $(17.1 \pm 9.8 \mathrm{bpm})(\mathrm{p}<0.001)$. HRR3 values were statistically significantly higher in patients 
with hypertension $(38.3 \pm 14.6 \mathrm{bpm})$ than in those without hypertension $(31.9 \pm 15.8 \mathrm{bpm})(\mathrm{p}<0.001)$.

Diabetes mellitus was present in $59(22.7 \%)$ patients. HRR1 values were statistically significantly higher in patients without diabetes $(19.4 \pm 10.3 \mathrm{bpm})$ than in those with diabetes $(14.7 \pm 9.4 \mathrm{bpm})(\mathrm{p}=0.002)$. HRR3 values were not statistically significantly higher in patients with diabetes $(34 \pm 15.2 \mathrm{bpm})$ than in those without diabetes $(29.8 \pm 17.3 \mathrm{bpm})(\mathrm{p}=0.07)$.

The stress test was ceased as a result of chest pain in $33(12.7 \%)$ patients. HRR1 values were not statistically significantly different in patients without pain $(18.5 \pm 10.3$ $\mathrm{bpm})$ compared to those with pain $(17.1 \pm 9.8 \mathrm{bpm})(\mathrm{p}=0.4)$. HRR3 values were not statistically significantly different in patients without pain $(32.8 \pm 15.8 \mathrm{bpm})$ compared to those with pain $(34.9 \pm 15.9 \mathrm{bpm})(\mathrm{p}=0.4)$.

The stress test was ceased as a result of fatigue in 122 (46.9\%) patients. HRR1 values were not statistically significantly differentin patients without fatigue $(18.3 \pm 9.2$ $\mathrm{bpm})$ compared to those with fatigue $(18.5 \pm 11.5 \mathrm{bpm})$ $(\mathrm{p}=0.8)$. HRR3 values were not statistically significantly different in patients without fatigue $(34.2 \pm 14.8 \mathrm{bpm})$ compared to those with fatigue $(31.8 \pm 16.7 \mathrm{bpm})(\mathrm{p}=0.2)$.

During the test effort, dyspnea was observed in $181(69.6 \%)$ patients. HRR1 values were not statistically significantly different in patients without dyspnoea $(19.4 \pm 11.5 \mathrm{bpm})$ compared to those with dyspnea $(17.9 \pm 9.7$ bpm) $(\mathrm{p}=0.2)$. HRR3were not statistically significantly different in patients without dyspnea $(33.4 \pm 17.4 \mathrm{bpm})$ compared to those with dyspnea $(32.9 \pm 15 \mathrm{bpm})(\mathrm{p}=0.7)$.

During the stress test, pressor response was observed in $90(34.6 \%)$ patients. HRR1 were not statistically significantly different in patients without pressor response $(18.5 \pm 9.9 \mathrm{bpm})$ than in those with pressor response $(18.3 \pm 10.6 \mathrm{bpm}) \quad(\mathrm{p}=0.8)$. HRR3values were not statistically significantly different in patients without pressor response $(31.5 \pm 16 \mathrm{bpm})$ compared to those with pressor response $(33 \pm 15 \mathrm{bpm})(\mathrm{p}=0.1)$.

The lipid profile was determined for the patients in the study and the following average values were obtained: total cholesterol $194 \pm 46.9 \mathrm{mg} / \mathrm{dl}$, LDL cholesterol $121.8 \pm 38.7 \mathrm{mg} / \mathrm{dl}$, HDL cholesterol $37.7 \pm 106 \mathrm{mg} / \mathrm{dl}$ and triglycerides $167.6 \pm 88.7 \mathrm{mg} / \mathrm{dl}$.

There was no statistically significant correlation between HRR1values and cholesterol $(\mathrm{r}=-0.039 ; \mathrm{p}=0.5)$, LDL cholesterol $(\mathrm{r}=0.031 ; \mathrm{p}=0.6)$, HDL cholesterol $(\mathrm{r}=-$ $0.075 ; \mathrm{p}=0.2)$. There was a low negative correlation between HRR1 values and triglyceride levels $(\mathrm{r}=-0.184$; $\mathrm{p}=0.003$ ).

There was no statistically significant correlation between HRR3 values and cholesterol levels $(\mathrm{r}=0.014$; $\mathrm{p}=0.8)$, LDL cholesterol $(\mathrm{r}=0.051 ; \mathrm{p}=0.4)$. There was a low positive correlation between HRR3 values and HDL cholesterol $(\mathrm{r}=0.124 ; \mathrm{p}=0.04)$.

To determine the independent association of certain factors with HRR1 values, we built a predictive model using multiple linear regression (Tab. 2). The model included variables that achieved a $p$ value of $<0.05$ in the univariate analysis. Male gender, the presence of hypertension, diabetes mellitus and triglyceride levels were independently associated with HRR1 variability. The proposed model explains $21.2 \%$ of HRR1 variability.

Table 2. Multiple linear regression for HRR1.

\begin{tabular}{|c|c|c|c|c|c|}
\hline & \multicolumn{2}{|c|}{$\begin{array}{l}\text { Unstandardized } \\
\text { Coefficients }\end{array}$} & \multirow{2}{*}{$\mathrm{P}$} & \multicolumn{2}{|c|}{$\begin{array}{l}95.0 \% \text { Confidence } \\
\text { Interval for B }\end{array}$} \\
\hline & B & $\begin{array}{l}\text { Std. } \\
\text { Error }\end{array}$ & & $\begin{array}{l}\text { Lower } \\
\text { Bound }\end{array}$ & $\begin{array}{l}\text { Upper } \\
\text { Bound }\end{array}$ \\
\hline Age & -0.03 & 0.06 & 0.5 & -0.15 & 0.08 \\
\hline Male gender & -3.60 & 1.16 & 0.002 & -5.89 & -1.32 \\
\hline HTN yes/no & -5.14 & 1.66 & 0.002 & -8.40 & -1.87 \\
\hline Diabetes & -2.51 & 1.42 & 0.07 & -5.32 & 0.29 \\
\hline CIC & -5.89 & 1.25 & $<0.001$ & -8.36 & -3.41 \\
\hline Triglycerides & -0.01 & 0 & 0.03 & -0.02 & 0 \\
\hline
\end{tabular}

To determine the independent association of certain factors with HRR3 values, we built a predictive model using multiple linear regression (Tab. 3). The model included variables that achieved a $p$ value of $<0.05$ in the univariate analysis. Male gender, the presence of hypertension and triglyceride levels were independently associated with HRR3variability. The proposed model explains $13.7 \%$ of HRR3variability.

Table 3. Multiple linear regression for HRR3.

\begin{tabular}{|c|c|c|c|c|c|}
\hline & \multicolumn{2}{|c|}{$\begin{array}{c}\text { Unstandardized } \\
\text { Coefficients }\end{array}$} & \multirow{2}{*}{$\mathrm{P}$} & \multicolumn{2}{c|}{$\begin{array}{c}95.0 \% \text { Confidence } \\
\text { Interval for B }\end{array}$} \\
\cline { 2 - 3 } \cline { 6 - 6 } & $\mathrm{B}$ & $\begin{array}{c}\text { Std. } \\
\text { Error }\end{array}$ & & $\begin{array}{c}\text { Lower } \\
\text { Bound }\end{array}$ & $\begin{array}{c}\text { Upper } \\
\text { Bound }\end{array}$ \\
\hline Age & -0.08 & 0.09 & 0.39 & -0.27 & 0.11 \\
\hline Gender & -8.66 & 1.90 & $<0.001$ & -12.41 & -4.91 \\
\hline HTN yes/no & -5.42 & 2.66 & 0.04 & -10.66 & -0.17 \\
\hline Diabetes & -3.03 & 2.33 & 0.1 & -7.64 & 1.56 \\
\hline Triglycerides & -0.02 & 0.01 & 0.01 & -0.04 & 0 \\
\hline HDL & -0.04 & 0.09 & 0.6 & -0.22 & 0.13 \\
\hline
\end{tabular}

\section{Discussion}

The autonomic nervous system is difficult to investigate because thereis afine controlof the cardiovascular system from the arterial and venous constriction to HR. In normal individuals dual sympathetic and parasympathetic innervation allows simultaneous antagonistic actions. Sympathetic nervous system increases stroke volume, 
HR, arterial and venous constriction increases cardiac contractility while inhibiting parasympathetic functions. Autonomic dysfunction is involved in the development of cardiovascular risk factors like hypertension, diabetes and was directly related to morbidity and mortality due to coronary heart disease (including sudden cardiac death) and total mortality.

In the present study we evaluated the possible influence of clinical and biological parameters of HRR in patients who had cardiovascular stress test. Although many variables in the univariate analysis were associated with HRR, in the multivariate analysis only a few were independently associated with HRR.

Elderly patients had slower heart rate recovery at 1 minute after effort. This is demonstrated by the low negative correlation between age and HRR1 values. As part of multivariate analysis, age did not have an independent influence on HRR1, probably due to the much greater impact of comorbidities (such as hypertension, CIC). HRR could be altered in the elderly probably due to the reduced response of beta-adrenergic receptors [20]. There are studies showing a connection between age and HRR, but they did not include patients with significant comorbidities, such as cardiovascular disease or severe respiratory diseases [21].

In our study, female patients recovered significantly better the heart rate, at 1 minute and 3 minutes after effort compared to the males. This difference was maintained in multivariate analysis, independent of age or comorbidities of patients. Several studies have determined that the autonomic nervous system presents significant functional differences between men and women [22,23].

These differences are evident regarding the cardiovascular system, womens having a significantly higher variability of heart rate recovery after effort. Increased parasympathetic activity reflects the beneficial cardiovascular stress periods, when shown a reduced incidence of ventricular ectopic events in women compared with men $[24,25]$.

Gender differences in variability of the autonomic nervous system function can be explained, at least in part by sex hormone levels. Thus, in postmenopausal women, there are no visible differences in cardiac modulation compared to males of the same age [26,27].

These differences translates also on the prognosis in subjects with heart failure, thus HRR is a more accurate prognostic marker in women than in men [28].

The presence of ischemic heart disease was the most important factor independently associated with HRR1. Although CI patients had lower values of HRR at 1 and 3 minutes after exercise, the difference compared with patients without CI was low and did not remain independent in the multivariate analysis. The link between a low HRR and negative cardiovascular outcomes is well established $[29,30]$. The mechanism underlying this relationship is based on the imbalance between the sympathetic and parasympathetic nervous systems. There are studies that have shown that an abnormal HRR is predictive for the presence of coronary artery disease, even in the absence of any specific ECG [31,32]. Coronary angiography studies have demonstrated the existence of advanced atherosclerotic status in patients with reduced HRR [33].

Triglyceride values were negatively correlated with both HRR3 and HRR1 and independent of other factors present in the multivariate analysis. The ratio triglyceride/HDL-cholesterol is strongly correlated with insulin resistance, which is associated with a reduced parasympathetic activity [34,35]. Shishehbor and collaborators have demonstrated a strong association between triglycerides and HRR, even after adjustment for blood glucose [36].

One of the limitations of the study is the lack of coronary angiography in all patients in the study, which could help us better estimate the severity of ischemic heart disease.

\section{Conclusions}

HRR could be a simple, non-invasive method for identification of high risk patients and for predicting patient outcomes during cardiovascular recovery.

Response and recovery from exercise heart exercise are mediated by the dynamic interaction between the sympathetic and parasympathetic nervous systems.

Autonomic dysfunction is involved in the development of cardiovascular risk factors like hypertension, diabetes, dyslipidemia and was directly related to the morbidity and mortality caused by coronary heart disease.

\section{References}

1. Freeman JV, Dewey FE, Hadley DM, Myers J, Froelicher VF. Autonomic nervous system interaction with the cardiovascular system during exercise. Prog Cardiovasc Dis. 2006;48:342-362. 2. Perini R, Veicsteinas A. Heart rate variability and autonomic activity at rest and during exercise in various physiological conditions. Eur J Appl Physiol. 2003;90:317-325.

3. Borresen J, Lambert MI. Autonomic control of heart rate during and after exercise : measurements and implications for monitoring training status. Sports Med. 2008;38:633-646.

4. Cardus D, Spencer WA. Recovery time of heart frequency in healthy men: its relation to age and physical condition. Arch Phys Med Rehabil. 1967;48:71-77.

5. Coote JH. Recovery of heart rate following intense dynamic exercise. Exp Physiol. 2010;95:431-440.

6. Savin WM, Davidson DM, Haskell WL. Autonomic contribution to heart rate recovery from exercise in humans. J Appl Physiol Respir Environ Exerc Physiol. 1982;53:1572-1575.

7. Crouse S, Sterling J, Tolson H, Hasson S. The effect of betaandrenergic blockade on heart rate recovery from exercise. J Cardiopulmonary Rehabilitation. 1989;9:202-206.

8. Kannankeril PJ, Goldberger JJ. Parasympathetic effects on cardiac electrophysiology during exercise and recovery. Am J Physiol Heart Circ Physiol. 2002;282:H2091-H2098. 
9. Kannankeril PJ, Le FK, Kadish AH, Goldberger JJ. Parasympathetic effects on heart rate recovery after exercise. J Investig Med. 2004;52:394-401.

10. Ng J, Sundaram S, Kadish AH, Goldberger JJ. Autonomic effects on the spectral analysis of heart rate variability after exercise. Am J Physiol Heart Circ Physiol. 2009;297:H1421-H1428.

11. Pierpont GL, Voth EJ. Assessing autonomic function by analysis of heart rate recovery from exercise in healthy subjects. Am J Cardiol. 2004;94:64-68.

12. Imai K, Sato H, Hori M, Kusuoka H, Ozaki H, Yokoyama $\mathrm{H}$, et al. Vagally mediated heart rate recovery after exercise is accelerated in athletes but blunted in patients with chronic heart failure. J Am Coll Cardiol. 1994;24:1529-1535.

13. Alberti KG, Zimmet PZ. Definition, diagnosis and classification of diabetes mellitus and its complications. Part 1: diagnosis and classification of diabetes mellitus provisional report of a WHO consultation. Diabet Med. 1998;15:539-553.

14. Cole CR, Blackstone EH, Pashkow FJ, Snader CE, Michael S. Lauer MS. Heart-rate recovery immediately after exercise as a predictor of mortality. N Engl J Med. 1999;341:1351-1357.

15. Morshedi-Meibodi A, Larson MG, Levy D, O’Donnell CJ, Vasan RS. Heart rate recovery after treadmill exercise testing and risk of cardiovascular disease events (The Framingham Heart Study). Am J Cardiol. 2002;90:848-852.

16. Mora S, Redberg RF, Cui Y, Whiteman MK, Flaws JA, Sharrett $\mathrm{AR}$, et al. Ability of exercise testing to predict cardiovascular and all-cause death in asymptomatic women: a 20-year follow-up of the lipid research clinics prevalence study. JAMA. 2003;290:16001607.

17. Brinkworth GD, Noakes M, Buckley JD, Clifton PM. Weight loss improves heart rate recovery in overweight and obese men with features of the metabolic syndrome. Am Heart J. 2006;152:693.e1-6.

18. Watanabe J, Thamilarasan M, Blackstone EH, Thomas JD, Lauer MS. Heart rate recovery immediately after treadmill exercise and left ventricular systolic dysfunction as predictors of mortality: the case of stress echocardiography. Circulation. 2001;104:1911-1916.

19. Pitsavos CH, Chrysohoou C, Panagiotakos DB, Kokkinos P, Skoumas J, Papaioannou I, et al. Exercise capacity and heart rate recovery as predictors of coronary heart disease events, in patients with heterozygous familial hypercholesterolemia. Atherosclerosis. 2002;173:347-352.

20. Takahashi T, Okada A, Hayano J, Tamura T. Influence of cooldown exercise on autonomic control of heart during rate recovery from dynamic exercise. Front Med Biol Eng. 2002;11:249-259.

21. Antelmi I, Chuang EY, Grupi CJ, Latorre MR, Mansur AJ. Heart rate recovery after treadmill electrocardiographic exercise stress test and 24-hour heart rate variability in healthy individuals. Arq Bras Cardiol. 2008;90(6):380-385.

22. Amiel SA, Maran A, Powrie JK, Umpleby AM, Macdonald IA. Gender differences in counterregulation to hypoglycaemia. Diabetologia. 1993;36(5):460-464.

23. Davis SN, Cherrington AD, Goldstein RE, Jacobs J, Price L. Effects of insulin on the counterregulatory responseto equivalent hypoglycemia in normal females. Am J Physiol. 1993;265(5 Pt.
1):E680-E689.

24. Airaksinen KE, Ikäheimo MJ, Linnaluoto M, Tahvanainen KU, Huikuri HV. Gender difference in autonomic and hemodynamic reactions to abrupt coronary occlusion. J Am Coll Cardiol. 1998;31(2):301-306.

25. Mendonca GV, Heffernan KS, Rossow L, Guerra M, Pereira FD, Fernhall B. Sex differences in linear and nonlinear heart rate variability during early recovery from supramaximal exercise. Appl Physiol Nutr Metab. 2010;35(4):439-446.

26. Kuo TB, Lin T, Yang CC, Li CL, Chen CF, Chou P. Effect of aging on gender differences in neural control of heart rate. Am J Physiol. 1999;277(6 Pt 2):H2233-H2239.

27. Dart AM, Du XJ, Kingwell BA. Gender, sex hormones and autonomic nervous control of the cardiovascular system. Cardiovasc Res. 2002;53(3):678-687.

28. Arena R, Myers J, Abella J, Pinkstaff S, Peberdy MA, Bensimhon D, et al. Prognostic characteristics of heart rate recovery according to sex patients with heart failure. Int J Cardiol. 2010;145(2):293-294.

29. Hendel RC, Berman DS, Di Carli MF, Heidenreich PA, Henkin RE, Pellikka PA, et al. ACCF/ASNC/ACR/AHA/ASE/ SCCT/SCMR/SNM 2009 Appropriate Use Criteria for Cardiac Radionuclide Imaging: A Report of the American College of Cardiology Foundation Appropriate Use Criteria Task Force, the American Society of Nuclear Cardiology, the American College of Radiology, the American Heart Association, the American Society of Echocardiography, the Society of Cardiovascular Computed Tomography, the Society for Cardiovascular Magnetic Resonance, and the Society of Nuclear Medicine. Circulation. 2009; 119: e561-e587.

30. Nishime EO, Cole CR, Blackstone EH, Pashkow FJ, Lauer MS. Heart rate recovery and treadmill exercise score as predictors of mortality in patients referred for exercise ECG. JAMA. 2000;284:1392-1398.

31. Gera N, Taillon LA, Ward RP. Usefulness of abnormal heart rate recovery on exercise stress testing to predict high-risk findings on single-photon emission computed tomography myocardial perfusion imaging in men. Am J Cardiol. 2009;103(5):611-614.

32. Ghaffar S, Kazemi B, Aliakbarzadeh P. Abnormal heart rate recovery after exercise predicts coronary artery disease severity. Cardiol J. 2011;18(1):47-54.

33. Vivekananthan DP, Blackstone EH, Pothier CE, Lauer MS. Heart rate recovery after exercise is a predictor of mortality, independent of the angiographic severity of coronary disease. J Am Coll Cardiol. 2003;42:831-838.

34. Reaven GM, Lithell H, Landsberg L. Hypertension and associated metabolic abnormalities: the rolls of insulin resistance and the sympathoadrenal system. N Engl J Med. 1996;334:374381.

35. McLaughlin T, Abbasi F, bald K, Chu J, LaMendola C, Reaven G. Use of metabolic markers to identify overweight individuals who have insulin resistant. Ann Intern Med. 2003;139:802-809.

36. Shishehbor MH, Hoogwerf BJ, Lauer MS. Association of triglyceride-to-HDL cholesterol ratio with heart rate recovery. Diabetes Care. 2004;27(4):936-941. 